\title{
OBSERVATIONS ON THE FUNCTIONAL HOMOGENEITY OF THE NEPHRON POPULATION IN THE CHRONICALLY DISEASED KIDNEY OF THE DOG *
}

\author{
By NEAL S. BRICKER † TADEUSZ ORLOWSKI, $\ddagger$ S. WESLEY KIME, JR.§ AND \\ PETER A. F. MORRIN \| \\ (From the Department of Medicine, Renal Division, Washington University School of Medicine, \\ St. Louis, Mo.)
}

(Submitted for publication June 11, 1960; accepted July 8, 1960)

Most forms of chronic renal disease result in extensive structural alterations of the renal parenchyma. Both glomeruli and tubules may exhibit a spectrum of anatomic abnormalities which give the constituent nephrons an appearance of extraordinary heterogenity. The degree to which these diversified structural changes alter the function of the surviving nephrons is of central importance to the clarification of the functional organization of the diseased kidney. In the present studies an attempt has been made to evaluate the functional homogeneity of the chronically diseased kidney in the dog, using the glucose titration technique $(1,2)$. Three forms of experimental renal disease have been employed. In each, anatomic heterogeneity of the renal parenchyma was a striking and consistent feature. In order to compare the function of the diseased organs with kidneys uninvolved by disease, the lesions were induced in one kidney only, and the contralateral kidney served as a control in each animal.

\section{METHODS}

Twelve glucose titration experiments were performed on 9 young, adult, trained, female mongrel dogs with unilateral renal disease. Four animals had unilateral pyelonephritis (3), three had unilateral aminonucleoside nephritis (4) and two had unilateral antikidney serum nephritis (5).

The animals were studied in the fasting and unanesthetized state and in the standing position. Thirty $\mathrm{ml}$ per $\mathrm{kg}$ of tap water was administered by nasogastric tube

\footnotetext{
* Supported by the National Institutes of Health (Grant A-2667-C3), and the Department of the Army, Research and Development Branch (Contract no. DA-49-007-MD-

$\dagger$ Established Investigator, American Heart Associa-

$\ddagger$ Research Fellow, Rockefeller Foundation.

§ U.S.P.H.S. Post-doctoral Research Fellow.

II American Heart Association Research Fellow.
} 772). tion. in advance of the experiment in order to insure adequate urine flows during the initial urine collection periods. Glucose was infused intravenously in 0.45 per cent saline at the rate of $5.0 \mathrm{ml}$ per minute throughout the experiment. Four levels of glucose infusion were employed. Three per cent glucose was infused during a 30 to 40 minute equilibration period and the first 3 clearance periods. Eight per cent glucose was then infused during a 5 to 15 minute equilibration period and the 3 succeeding clearance periods. Thereafter, 11 per cent glucose was infused and 3 urine collections were made without an intervening period of equilibration. Finally 20 per cent glucose was infused, a 30 minute equilibration period was allowed to assure plasma glucose levels well in excess of the tubular reabsorptive maximum and the last 3 clearance periods were obtained. Urine from the diseased and contralateral control kidneys was collected simultaneously from permanent cystotomy tubes draining individual hemibladders. Continuous arterial blood samples were collected throughout each urine collection period by means of an indwelling femoral arterial polyethylene catheter.

Glomerular filtration rate was estimated by the exogenous creatinine clearance. Creatinine was measured according to the method of Bonsnes and Taussky (6) ; and over the range of glucose concentrations observed in plasma and urine, no interference with creatinine analysis occurred. Glucose was determined using a specific enzymatic (i.e., glucose oxidase) technique (7). Additional details of the experimental procedures employed have been described previously (4).

\section{RESULTS}

In all dogs the diseased kidney was contracted and histologic examination revealed marked structural abnormalities, the details of which varied with the type of underlying renal disease. The values for glomerular filtration rate (GFR) and maximal rate of glucose reabsorption ( $\left.T \mathrm{~m}_{\text {glucose }}\right)$ were consistently decreased for the diseased kidneys relative to the contralateral control kidneys. Values for GFR ranged from 3.6 to $21 \mathrm{ml}$ per minute (mean, 12) for the diseased, and from 22 to 
TABLE I

Glomerular filtration rate $(G F R)$, maximal rate of glucose reabsorption $\left(T m_{\text {olucose }}\right)$ and $G F R / T m_{\text {olucose }}$ ratios for diseased and contralateral control kidneys

\begin{tabular}{|c|c|c|c|c|c|c|c|c|}
\hline \multirow[b]{2}{*}{ Dog } & \multirow[b]{2}{*}{ Lesion* } & \multirow[b]{2}{*}{ Weight } & \multicolumn{2}{|c|}{ GFR } & \multicolumn{2}{|c|}{$T m_{g}$ lucose } & \multicolumn{2}{|c|}{$\mathrm{GFR} / \mathrm{Tm}_{\mathrm{g} \text { lucose }}$} \\
\hline & & & Exp. & Cont. & Exp. & Cont. & Exp. & Cont. \\
\hline & & $\mathrm{kg}$ & \multicolumn{2}{|c|}{$m l / m i n$} & \multicolumn{2}{|c|}{$m g / m i n$} & & \\
\hline 1 & Pyelo. & 9.5 & $\begin{array}{l}10 \\
11\end{array}$ & $\begin{array}{l}23 \\
22\end{array}$ & $\begin{array}{l}44 \\
42\end{array}$ & $\begin{array}{l}87 \\
81\end{array}$ & $\begin{array}{l}0.23 \\
0.26\end{array}$ & $\begin{array}{l}0.26 \\
0.27\end{array}$ \\
\hline 2 & Pyelo. & 10.5 & $\begin{array}{l}16 \\
15\end{array}$ & $\begin{array}{l}29 \\
23\end{array}$ & $\begin{array}{l}52 \\
51\end{array}$ & $\begin{array}{l}90 \\
78\end{array}$ & $\begin{array}{l}0.31 \\
0.30\end{array}$ & $\begin{array}{l}0.32 \\
0.30\end{array}$ \\
\hline 3 & Pyelo. & 10.5 & 3.6 & 46 & 14 & 176 & 0.26 & 0.26 \\
\hline 4 & Pyelo. & 15.0 & 24 & 51 & 65 & 135 & 0.38 & 0.38 \\
\hline 5 & A.N. & 8.0 & 6.2 & 37 & 15 & 91 & 0.39 & 0.40 \\
\hline & & & 4.8 & 30 & 12 & 77 & 0.39 & 0.39 \\
\hline 6 & A.N. & 15.2 & 16 & 50 & 57 & 186 & 0.28 & 0.27 \\
\hline 7 & A.N. & 15.4 & 18 & 45 & 49 & 113 & 0.37 & 0.39 \\
\hline 8 & A.K.S. & 13.7 & 22 & 42 & 69 & 148 & 0.32 & 0.28 \\
\hline 9 & A.K.S. & 15.9 & 4.6 & 44 & 22 & 202 & 0.21 & 0.22 \\
\hline
\end{tabular}

* Exp. and Cont. refer to experimental (i.e., diseased) and control kidneys. Pyelonephritis is designated as Pyelo., aminonucleoside nephritis as A.N., and antikidney serum nephritis as A.K.S.

$51 \mathrm{ml}$ per minute (mean, 37) for the control organs. Values for $\mathrm{Tm}_{\text {glucose }}$ ranged from 12 to 69 mg per minute (mean, 29) for the diseased kidneys, and from 77 to $202 \mathrm{mg}$ per minute (mean, 119) for the control organs. Of considerable interest is the fact that in all dogs, the ratios of $\mathrm{GFR} / \mathrm{Tm}_{\text {glucose }}$ for the separate kidneys were quite comparable. Values for GFR, Tm glucose and GFR/ $\mathrm{Tm}_{\text {glncose }}$ are shown in Table I.

In Table II, a representative glucose titration experiment is shown for an animal with unilateral renal disease. Plasma glucose concentrations were increased from an initial fasting level of 80 to $714 \mathrm{mg}$ per $100 \mathrm{ml}$. Glucose reabsorption was essentially complete bilaterally until the plasma glucose concentration exceeded $250 \mathrm{mg}$ per 100 $\mathrm{ml}$. Some degree of glycosuria occurred bilaterally before the load of glucose equaled the Tm values (Period 5), and a limited splay in the respective titration curves resulted. This was slightly more marked for the diseased than for the control kidney in this experiment (Period 6);

TABLE II

A glucose titration experiment in a representative dog with unilateral renal disease *

\begin{tabular}{|c|c|c|c|c|c|c|c|c|c|c|c|c|}
\hline \multirow[b]{2}{*}{ Period } & \multirow[b]{2}{*}{ Time } & \multirow[b]{2}{*}{$\begin{array}{l}\text { Plasma } \\
\text { glucose }\end{array}$} & \multicolumn{5}{|c|}{ Exp. kidney } & \multicolumn{5}{|c|}{ Control kidney } \\
\hline & & & GFR & $\begin{array}{c}\text { Glucose } \\
\text { excretion }\end{array}$ & $T_{\text {glucose }}$ & $\frac{\mathrm{T}}{\mathrm{Tm}}$ & $\frac{\text { Load }}{\mathrm{Tm}}$ & GFR & $\begin{array}{l}\text { Glucose } \\
\text { excretion }\end{array}$ & $\mathrm{T}_{\text {glucose }}$ & $\frac{\mathrm{T}}{\mathrm{Tm}}$ & $\frac{\text { Load }}{\mathrm{Tm}}$ \\
\hline & $\min$ & $\begin{array}{l}\mathrm{mg} / \\
100 \mathrm{ml}\end{array}$ & $\mathrm{ml} / \mathrm{min}$ & $m g / m i n$ & $m g / m i n$ & $3 \%$ & acose & $m l / m i n$ & $m g / m i n$ & $m g / m i n$ & & \\
\hline \multirow[t]{2}{*}{$\begin{array}{l}1 \\
2 \\
3\end{array}$} & $\begin{array}{r}0-16 \\
16-30 \\
30-40\end{array}$ & $\begin{array}{l}123 \\
136 \\
144\end{array}$ & $\begin{array}{l}14.5 \\
15.9 \\
15.2\end{array}$ & $\begin{array}{l}0 \\
0 \\
0\end{array}$ & $\begin{array}{l}17.8 \\
21.6 \\
21.8\end{array}$ & $\begin{array}{l}0.36 \\
0.43 \\
0.43\end{array}$ & $\begin{array}{l}0.36 \\
0.43 \\
0.43\end{array}$ & $\begin{array}{l}21.7 \\
23.2 \\
23.6\end{array}$ & $\begin{array}{l}0 \\
0 \\
0\end{array}$ & $\begin{array}{l}26.6 \\
31.6 \\
33.9\end{array}$ & $\begin{array}{l}0.34 \\
0.41 \\
0.44\end{array}$ & $\begin{array}{l}0.34 \\
0.41 \\
0.44\end{array}$ \\
\hline & \multicolumn{12}{|c|}{$8 \%$ glucose } \\
\hline \multirow[t]{2}{*}{$\begin{array}{l}4 \\
5 \\
6\end{array}$} & $\begin{array}{l}49-62 \\
62-75 \\
75-89\end{array}$ & $\begin{array}{l}252 \\
298 \\
350\end{array}$ & $\begin{array}{l}14.6 \\
15.3 \\
15.1\end{array}$ & $\begin{array}{l}0.3 \\
2.4 \\
5.4\end{array}$ & $\begin{array}{l}36.4 \\
43.2 \\
47.4\end{array}$ & $\begin{array}{l}0.72 \\
0.86 \\
0.94\end{array}$ & $\begin{array}{l}0.73 \\
0.91 \\
1.04\end{array}$ & $\begin{array}{l}23.8 \\
23.6 \\
24.7\end{array}$ & $\begin{array}{l}0.4 \\
3.8 \\
8.9\end{array}$ & $\begin{array}{l}59.5 \\
66.5 \\
77.6\end{array}$ & $\begin{array}{l}0.77 \\
0.85 \\
1.00\end{array}$ & $\begin{array}{l}0.77 \\
0.91 \\
1.11\end{array}$ \\
\hline & \multicolumn{12}{|c|}{$11 \%$ glucose } \\
\hline \multirow[t]{2}{*}{$\begin{array}{l}7 \\
8 \\
9\end{array}$} & $\begin{array}{r}89-103 \\
103-119 \\
119-129\end{array}$ & $\begin{array}{l}405 \\
490 \\
500\end{array}$ & $\begin{array}{l}15.8 \\
14.6 \\
14.5\end{array}$ & $\begin{array}{l}10.4 \\
20.5 \\
26.6\end{array}$ & $\begin{array}{l}53.6 \\
51.0 \\
45.9\end{array}$ & $\begin{array}{l}1.07 \\
1.02 \\
0.91\end{array}$ & $\begin{array}{l}1.27 \\
1.42 \\
1.44\end{array}$ & $\begin{array}{l}25.7 \\
22.1 \\
23.5\end{array}$ & $\begin{array}{l}17.8 \\
33.4 \\
42.0\end{array}$ & $\begin{array}{l}86.3 \\
74.9 \\
75.5\end{array}$ & $\begin{array}{l}1.11 \\
0.96 \\
0.97\end{array}$ & $\begin{array}{l}1.34 \\
1.39 \\
1.51\end{array}$ \\
\hline & \multicolumn{12}{|c|}{$20 \%$ glucose } \\
\hline $\begin{array}{l}10 \\
11\end{array}$ & $\begin{array}{l}142-150 \\
150-159\end{array}$ & $\begin{array}{l}664 \\
714\end{array}$ & $\begin{array}{l}15.7 \\
15.6\end{array}$ & $\begin{array}{l}51.7 \\
60.2\end{array}$ & $\begin{array}{l}52.5 \\
51.2\end{array}$ & $\begin{array}{l}1.05 \\
1.02\end{array}$ & $\begin{array}{l}2.08 \\
2.22\end{array}$ & $\begin{array}{l}22.7 \\
23.2\end{array}$ & $\begin{array}{l}76.2 \\
87.6\end{array}$ & $\begin{array}{l}74.5 \\
78.0\end{array}$ & $\begin{array}{l}0.96 \\
1.00\end{array}$ & $\begin{array}{l}1.94 \\
2.13\end{array}$ \\
\hline
\end{tabular}

* $\mathrm{T}_{\mathrm{z} \text { lucose }}$ refers to glucose reabsorption. Load refers to the filtered load of glucose and is equal to the product of GFR $\times$ plasma glucose con-

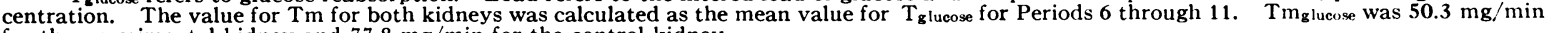
for the experimental kidney and $77.8 \mathrm{mg} / \mathrm{min}$ for the control kidney. 


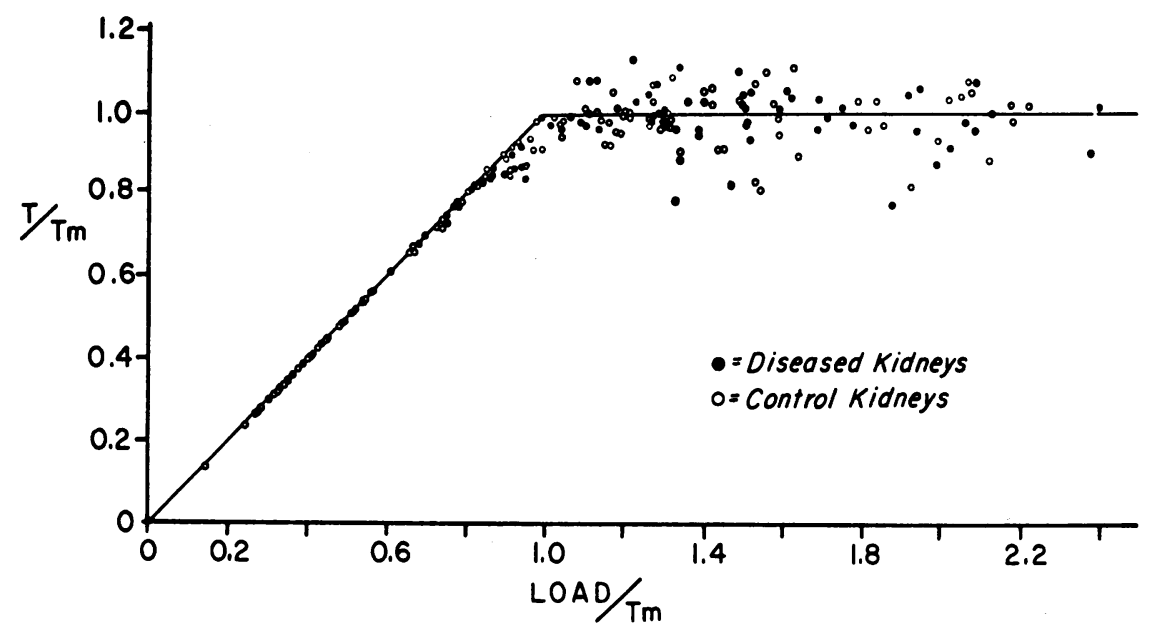

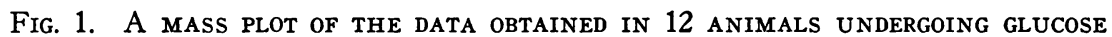
TITRATION EXPERIMENTS. $\mathrm{T} / \mathrm{Tm}$ refers to the observed rate of glucose reabsorption expressed as a fraction of the $\mathrm{Tm}$ for the same kidney. Load/ $\mathrm{Tm}$ refers to the filtered load expressed as a fraction of the $\mathrm{Tm}$.

however, this relationship was not a consistent one.

In Figure 1, a mass plot is shown of the data obtained in 12 experiments; 120 observations for the diseased kidneys are compared with the same num- ber of observations, simultaneously obtained, for the control kidneys. Gross inspection of the data suggests that there is no greater titration splay for the diseased than for the normal organs.

Figure 2 depicts the mean smoothed titration

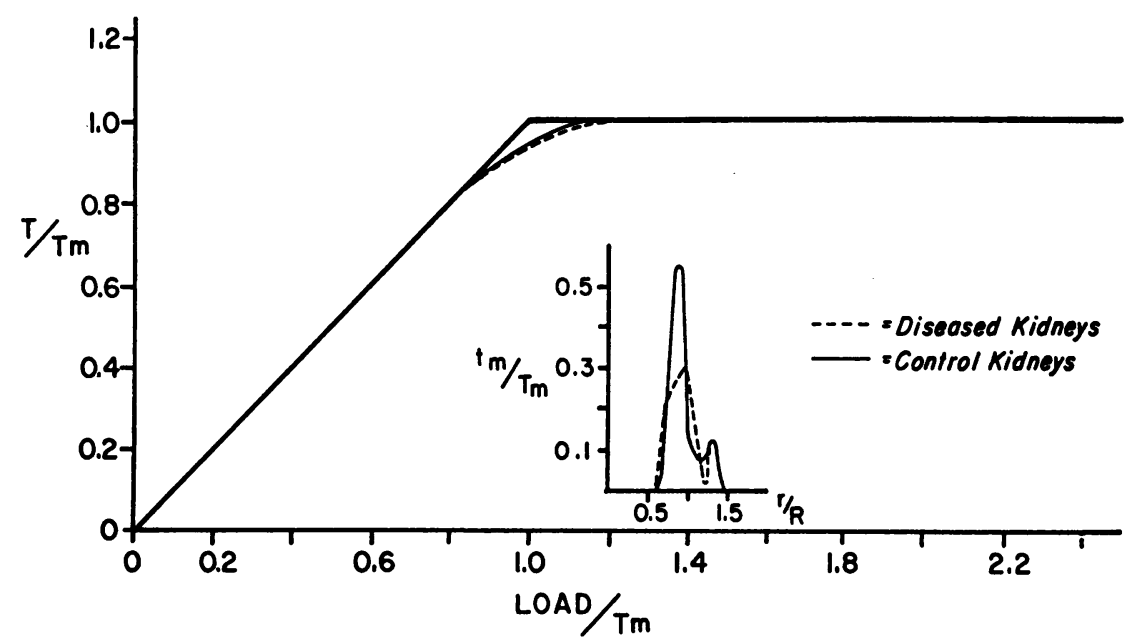

Fig. 2. The mean titration curves for the group data PResented in Figure 1. The frequency distribution curves for the two sets of group data are shown in the insert. The symbols, $\mathrm{tm} / \mathrm{Tm}$ and $\mathrm{r} / \mathrm{R}$ are those conventionally used for this plot: $\mathrm{tm} / \mathrm{Tm}$ represents the rate of glucose reabsorption in saturated nephrons expressed as a fraction of the whole kidney $\mathrm{Tm}$, and thus this term serves as an index of the fraction of the total nephron population; $r / R$ provides a ratio of the glomerular tubular balance (with respect to glucose) for individual nephrons, or categories of nephrons, to the mean value for glomerular tubular balance for the whole kidney. A detailed discussion of the methods of calculating both the mean titration curves and the frequency distribution curves is contained in the paper by Smith and co-workers (2). 
curves obtained according to the method of Smith, Goldring, Chasis, Ranges and Bradley (2) for the group data shown in Figure 1. The shape of the curve for the diseased kidneys is essentially indistinguishable from that for the normal kidneys. Frequency distribution curves for the group data are shown in the insert in Figure 2. Statistical analysis of the two distribution curves shows no significant difference between either the mean values or the variances.

\section{DISCUSSION}

The glucose titration technique provides a physiologic means of exploring the functional homogeneity of the constituent nephrons of a given kidney. The rationale depends upon the assumptions, that for each functioning nephron: 1) the proximal tubule has a maximal rate at which it may transfer glucose (i.e., a $\mathrm{Tm}$ ); 2) reabsorption will be essentially complete until the $\mathrm{Tm}$ is achieved; and 3 ) the rate of glucose reabsorption will remain constant after the load exceeds the $\mathrm{Tm}$ and all filtered glucose in excess of the reabsorbed moiety will be excreted.

The titration is performed by increasing the concentration of glucose in the plasma progressively from normal levels to values sufficiently high to produce marked and sustained glycosuria. At any point in time, the load of glucose presented to the reabsorbing sites in each individual nephron represents the product of the volume of glomerular filtrate entering the unit times the concentration of glucose in the filtrate. Because all of the nephrons of a kidney are perfused by plasma of identical composition, the glucose concentration may be presumed to be the same for all functioning units. Hence any difference in the time of appearance of glycosuria between adjacent nephrons should reflect a corresponding difference in the balance between GFR and proximal glucose reabsorptive capacity. When applied to a whole kidney, therefore, the technique provides an index of the consistency of glomerulotubular balance (with respect to glucose) for the constituent nephrons.

If there is a uniform (i.e., homogeneous) relationship between filtration and glucose reabsorption, all nephrons should reach their $\mathrm{Tm}$ at the same plasma glucose concentration. Hence the filtered glucose should be completely reabsorbed until the plasma concentration exceeds a critical level; and thereafter the rate of glucose reabsorption should remain constant. However, if there is functional heterogeneity, the pattern should be different. Any group of nephrons in which the volume of filtrate is disproportionately large with respect to glucose reabsorptive capacity should reach $\mathrm{Tm}$ before the remaining units, and glucose should be delivered into the urine at a relatively low plasma glucose concentration. Alternatively, nephrons in which the volume of filtrate is disproportionately small relative to reabsorptive capacity should continue to reabsorb filtered glucose until plasma glucose concentrations become very high and after the remaining units have reached their $\mathrm{Tm}$.

Recently, Bradley, Laragh, Wheeler, MacDowell and Oliver (8) have reported observations which lend considerable authority to the glucose titration technique as a means of evaluating nephron homogeneity. These workers have found that in the dog, the relationship between glomerular and proximal tubular function as assessed by glucose titration curves correlates precisely with anatomic measurements of glomeruli and their attached tubules (i.e., glomerular area versus proximal tubular volume) in nephrons from the same kidneys which have been isolated by microdissection.

In the normal dog kidney, Shannon, Farber and Troast (9) and Kessler, Heidenreich and Pitts (10) have found that glucose reabsorption generally is essentially complete until the $\mathrm{Tm}$ is reached, following which reabsorption remains relatively constant despite increasing levels of plasma glucose. The fact that only a limited titration splay exists suggests that the nephron population of the normal dog kidney is basically a homogeneous one. The glucose titration technique would therefore appear to be well suited for the evaluation of the homogeneity of the nephron population of the diseased as well as the normal kidney. If anatomic heterogeneity results in corresponding functional heterogeneity, the diseased kidney should exhibit a splay in its titration curve considerably greater than that of a normal kidney.

In the present studies, glucose titration curves for the diseased kidneys of dogs were compared with the ideal curve for a homogeneous nephron 
population and also with the curves obtained simultaneously for contralateral kidneys which were free of disease.

Analysis of the data for individual animals revealed a high degree of comparability in titration curves between diseased and contralateral kidneys. In most instances the titration splay was minimal for both organs, and the magnitude of the splay typically was no greater for the diseased than for the contralateral kidneys. In a composite plot of group data (Figure 1), the titration splay was small for both diseased and intact organs; and the mean titration curves for the two sets of data were virtually superimposable. Comparison of the two frequency distribution curves showed no significant differences between the means or the variances. Statistically, therefore, the nephrons of the diseased kidneys could not be differentiated from those of the intact organs on the basis of their respective patterns of glucose transport.

Within the limits of accuracy of the glucose titration technique, the present observations are consistent with the thesis that the relationship between the volume of glomerular filtrate and the glucose reabsorptive capacity of the attached proximal tubules remains uniform in the surviving nephrons of the experimentally diseased kidney in the dog. At least two explanations may be considered for this phenomenon. The first is that the nephrons in a diseased kidney adhere functionally to what is tantamount to an all or none pattern. This would require that a nephron which sustains sufficient structural damage to either its glomerulus or proximal tubule to modify ultrafiltration or glucose transport would become functionless. The loss of nephron units could be either temporary or permanent depending on the nature of the pathologic process.

The second theoretic explanation for the observed functional homogeneity does not require an all or none hypothesis, but introduces certain other conceptual difficulties. This would hold that a decrease in the volume of glomerular filtrate induced by anatomic alterations in a filtering glomerulus would be accompanied by a proportional decrease in $\mathrm{Tm}_{\text {gluocse }}$ for the attached proximal tubule, such that the balance between filtration and glucose reabsorption would remain comparable with that for uninvolved nephrons as well as for other damaged but still functioning ne- phrons. Because the filtration fractions remain quite comparable between diseased and intact kidneys of individual animals, it is theoretically possible that a preferential decrease in GFR in an involved group of nephrons would be accompanied by a proportional decrease in postglomerular blood flow; and one possible means of autoregulation of glomerulotubular balance (with respect to glucose reabsorption) would involve a modulation of the rate of glucose transport by some function of the peritubular capillary blood flow. However, if a mechanism for autoregulation of glomerulotubular balance does exist in these diseased kidneys, it must also be capable of acting in a reverse fashion. Thus a primary decrease in glucose $\mathrm{Tm}$ due to an intrinsic structural abnormality in a proximal tubule would have to initiate a proportional decrease in the volume of fluid filtered by an appended glomerulus. In addition, the concept of autoregulation in damaged nephrons must explain the fact that some other tubular functions (e.g., $\mathrm{Tm}_{\mathrm{PAH}}, \mathrm{Tm}_{\text {phosphate, ammonia and titratable }}$ acid excretion) retain the same relationship to GFR in experimentally diseased kidneys as in contralateral control organs.

\section{SUM MARY}

Glucose reabsorption has been measured during rising plasma glucose concentrations in dogs with one of three types of chronic unilateral renal disease. The glucose titration curves for the diseased kidneys were compared with those simultaneously obtained for the contralateral intact organs. Both in studies on individual animals and in a composite plot of group data for 12 experiments on 9 dogs, the patterns of diseased and contralateral kidneys were quite similar. Analysis of the group data demonstrated no appreciable titration splay for either diseased or normal kidneys; and no significant differences were found between the frequency distribution curves for the two sets of data. On the basis of these observations, it has been suggested that the balance between the volume of glomerular filtrate and the glucose reabsorptive capacity of the attached proximal tubules remained uniform for the surviving nephrons of the diseased organs, despite evidence of marked anatomic heterogeneity. Within the limitations of the glucose titration method, the residual functioning nephrons of the experimentally diseased 
kidney in the dog would therefore appear to constitute a basically homogeneous population.

\section{REFERENCES}

1. Shannon, J. A., and Fisher, S. The renal tubular reabsorption of glucose in the normal dog. Amer. J. Physiol. 1938, 122, 765.

2. Smith, H. W., Goldring, W., Chasis, H., Ranges, H. A., and Bradley, S. E. The William Henry Welch Lectures. II. The application of saturation methods to the study of glomerular and tubular function in the human kidney. J. Mt Sinai Hosp. 1943, 10, 59.

3. Bricker, N. S., Dewey, R. R., and Lubowitz, H. Studies in experimental pyelonephritis: Simultaneous and serial investigation of a pyelonephritic and intact kidney in the same animal. Clin. Res. 1958, 6, 292.

4. Bricker, N. S., Stokes, J. M., Lubowitz, H., Dewey, R. R., Bernard, H. R., and Hartroft, P. M. Experimentally induced permanent unilateral renal disease in dogs. J. Lab. clin. Med. 1958, 52, 571.
5. Morrin, P. A. F., Bricker, N. S., and Kime, S. W., $\mathrm{Jr}$. Unilateral glomerulonephritis in the dog: An experimental model for the study of the functional capacity of the persisting nephrons of the diseased kidney. Clin. Res. 1959, 7, 277.

6. Bonsnes, R. W., and Taussky, H. On colorimetric determination of creatinine by the Jaffé reaction. J. biol. Chem. 1945, 158, 581.

7. Helmreich, E., and Eisen, H. N. The distribution and utilization of glucose in isolated lymph node cells. J. biol. Chem. 1959, 234, 1958.

8. Bradley, S. E., Laragh, J. H., Wheeler, H. O., MacDowell, M., and Oliver, J. Correlation of structure and function in the nephron population. Trans. Ass. Amer. Phycns 1959, 72, 294.

9. Shannon, J. A., Farber, S., and Troast, L. The measurement of glucose $\mathrm{Tm}$ in the normal dog. Amer. J. Physiol. 1941, 133, 752.

10. Kessler, R. H., Heidenreich, O. P. A., and Pitts, R. F. Evaluation of the cell separation hypothesis of autoregulation of renal blood flow and filtration rate. Glucose titrations in normal and anemic dogs. Amer. J. Physiol. 1957, 191, 501. 